$17^{\text {th }}$ International Congress of Metrology, 15002 (2015)

DOI: $10.1051 /$ metrology / 201515002

(C) Owned by the authors, published by EDP Sciences, 2015

\title{
Testing the reliability of humidity sensors through prolonged measurements traceable to calibration standards.
}

\author{
N. R. Nair ${ }^{1}$,a , P.W. McCarthy ${ }^{1}$, A.I. Heusch ${ }^{1}$ and R. Patz ${ }^{2}$ \\ ${ }^{1}$ Clinical Technology and Diagnostics Research Unit, University of South Wales, CF37 1DL, United Kingdom. \\ ${ }^{2}$ Computer Science and Electrical Engineering, University of Applied Science, Kiel 24149, Germany.
}

\begin{abstract}
This study looked at the accuracy of relative humidity sensors over a seven-month period at five locations. They were subjected to monthly traceable calibration in a climate-controlled chamber. We found the calibration output variance within sensors was smaller $(0.4 \pm 0.2 \% \mathrm{RH}: \mathrm{n}=5$ sensors, each of which was exposed to nine humidity levels in the climatic chamber) than the manufacturers specifications $( \pm 3.5 \% \mathrm{RH})$. The study found differences in sensor output variance, which might be related to their working environment. Powered sensors in low ambient RH environments showed minimal differences over time $(p>0.05)$ when compared to powered sensors exposed to higher humidity environments $(p<0.05)$. To the author's knowledge, there have been no previous reports on stability of calibration of humidity sensors over prolonged periods (seven months). This work gives the first indication of stability in relation to environmental conditions of use. It can be concluded that sensors should obtain regular recalibration if used continually (suggested every 6 months), however those in higher humidity environments appear to require more frequent re-calibration (approximately every 3 months).
\end{abstract}

\begin{abstract}
1 Introduction
In the less mobile or elderly population natural difference such as low activity and orthopaedic problems may cause them to spend prolonged periods of time sitting [1]. Prolonged sitting leads to the increased potential for skin maceration because of humidity build up [2-5] and increased friction between the person and seat or support surface [6-11] consequently skin damage is more likely. Some studies have indicated that body humidity could be an important property to investigate in order to understand the microclimate of the sitting interface between a person and seat surface $[3,4,12-17]$.
\end{abstract}

Prolonged exposure to increased humidity and liquid (from urinary incontinence and sweating) is known to damage skin viability [18] and may cause an additional rise in humidity of the microclimate between the person and seat surface. This raises an interesting possibility that there may be humidity variations in the microclimate (from sweating and urinary incontinence), which could be detected [17].

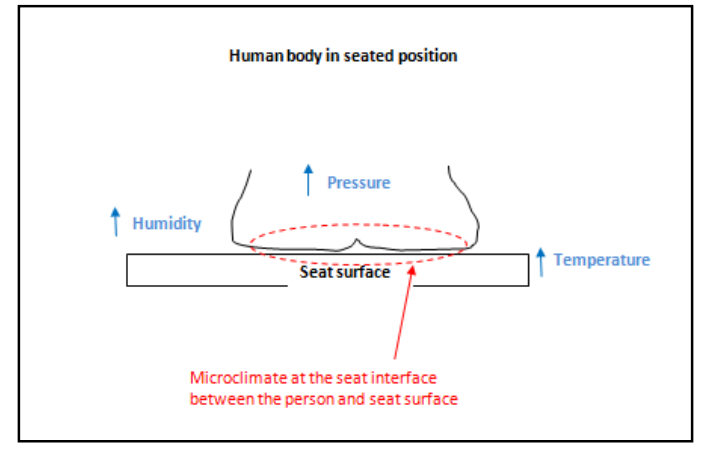

Figure 1. Skin integrity in sitting

Humidity is a property that is able to penetrate through materials it may be possible to achieve noninvasive and even 'non-person contact' measurements provided that the trigger levels of body exudates (urine excretion and perspiration) are fully understood [19]. However measuring the exact amount of humidity is challenging, on account of the changes in state of water in the atmosphere which can be either: ice, liquid or vapour depending on temperature and pressure [20,21]. 


\subsection{Humidity Sensor technology}

Sensors technologies used for incontinence detection devices have included infrared [22], accelerometry [23], electrical conduction (wires) [24] and peizoelectrics [25], however specific sensors designed to detect RH external to the human body have rarely been used [26]. Individual RH sensors appear unable to measure the full range of vapour levels, hence there is a range of methods and sensors that have been developed [27]. Humidity sensors can be ceramic, polymer based or solid moisture sensors, or chilled mirror hygrometers and each of these have varying calibration challenges [28, 29].

There has been an increasing demand for highly accurate humidity sensors in healthcare applications as well as for environmental and personal monitoring (enuresis sensors) particularly in smart homes [27]. Research and development aims to improve the performance of humidity sensors, especially in terms of: accuracy, reliability and speed of measurement [21, 28].

\subsection{Calibrating humidity sensors}

Determining the accuracy of RH sensors at the skin surface is of growing importance as this is an area that could benefit from continuous monitoring over prolonged periods [17]. For industrial use, the humidity sensors need to be calibrated against a traceable standard [30]. Calibration and testing carried out in laboratories in the UK is based on the ISO standard [31]. Accredited measurements in the UK have been developed by UKAS (member of the National Measurement Partnership) based on the ISO 17025 [32].

In order to correct for deviation in calibration over time, a measurement result can be related to a reference through a documented unbroken chain of calibrations, each contributing to the measurement uncertainty $[19,33]$. There are a variety of $\mathrm{RH}$ instruments available such as the RH sensors (capacitive and resistive) however their accuracies are not always optimal [34]. The accuracy of RH sensors usually falls within the limits of \pm 1 to 4 $\% \mathrm{RH}$, which is much better than the accuracy of the horse hair hygrometers at $\pm 10 \%$. However, as with many electronic sensors, calibration errors can render any output to be inaccurate. This suggests that there needs to be a high standard of calibration in order to meet the required higher accuracy available when using RH sensor technology. Although we must assume that RH sensors require and obtain a high standard calibration at the production phase, post sales use may depend on calibration stability for accuracy. Re-calibration, however, should be part of the ongoing maintenance to correct for any drift in measurement output [35].
The main objective of calibration is to ensure the accurate type of humidity measurement can be carried out in the right equipment with proven processes that allow the achievement of consistent results that are repeatable with thermal stability and uniformity [35]. The calibration device for RH sensors should include characteristics of accuracy, be inexpensive, quick, easy to operate and highly reliable. Sensors should be calibrated in a consistent and stable environment one that would prevent temperature fluctuations and moisture ingress (climatic chamber). To the author's knowledge, there has been no reported indication on how often calibration for humidity detection may be necessary to maintain accuracy; although length of time has been reported to lie anywhere between a few months to a year depending on usage [36].

This study aimed to evaluate existing humidity sensors [37] during use in various environments and conditions continuously over seven months. Sensors were subjected to regular monthly calibration in a climactic chamber, traceable to UK National Standards. The climatic chamber was chosen as it provides a controlled internal environment for humidity and temperature in a sealed area.

\section{Methodology}

Five new humidity sensors (Honeywell International USA: HIH 4000-004 RH sensors) were initially calibrated in a climatic chamber (traceable to national standards: chamber model, FS990-40V serial number 01-94-1705, The Design Environment Ltd, Ebbw Vale, UK; Certificate No. 6557). These sensors were exposed to a range of humidity levels (nine humidity levels: $30 \% \mathrm{RH}, 35$ $\%$ RH, $40 \%$ RH, $45 \%$ RH, $50 \%$ RH, $55 \%$ RH, 60 $\% \mathrm{RH}, 65 \% \mathrm{RH}, 70 \% \mathrm{RH}$ at $25{ }^{\circ} \mathrm{C}$ ) and was compared to the output of the chamber using linear regression model generation. The errors found $(0.4$ $\pm 0.2 \% \mathrm{RH})$ were within the reported manufacturers specifications $( \pm 3.5 \% \mathrm{RH})$. The sensors were placed in their respective locations (start of study at month 0 ). These locations were 5 different, yet relatively controlled, monitored indoor environments as follows: Temperature: kitchen $\left(22.5 \pm 1.1{ }^{\circ} \mathrm{C}\right)$; room $\left(22.3 \pm 0.9{ }^{\circ} \mathrm{C}\right)$. Humidity: kitchen $(49.2 \pm 8.1 \% \mathrm{RH})$; room $(46.6 \pm 6.7 \% \mathrm{RH})$. The options were that the sensors be either powered $(n=4$, of which there was one in a dark drawer, one on the wall facing a window (stable humidity, high light levels), one embedded in a seat (dark but higher humidity) and one in a kitchen (higher humidity); or unpowered $(\mathrm{n}=1)$ on an office table (Table 1). These studies were carried out at the University of South Wales. The humidity sensors were powered with a $6 \mathrm{~V}$ cell supply. The sensors were placed in their respective locations for 7 months (month 0 to 6). All humidity sensors were sampled once every month for six months in a 
climatic chamber (therefore the unpowered sensor was powered for a short time to allow calibration to take place). Every month the humidity sensors were manually removed from their housing and soldered onto one generic connection board. The calibration involved observing the sensors ability to accurately follow an ascending and descending humidity profile between $30 \% \mathrm{RH}$ and $70 \% \mathrm{RH}$ with $5 \% \mathrm{RH}$ incremental steps (10 minutes at each step)

In addition, the climatic chamber was set to a temperature of $25^{\circ} \mathrm{C}$. After calibration the sensors were connected back in their original battery powered housing at their respective locations.

Table 1. Humidity sensors in five locations

\begin{tabular}{|l|l|}
\hline Placement & Diagram \\
\hline $\begin{array}{l}\text { Sensors in a dark } \\
\text { drawer. }\end{array}$ \\
\hline $\begin{array}{l}\text { Sensors embedded in } \\
\text { a foam seat with a } \\
\text { cover. }\end{array}$ \\
\hline Sensors on the shelf. \\
\hline Sensors on a table \\
\hline $\begin{array}{l}\text { Sensors on kitchen } \\
\text { cabinet }\end{array}$ \\
\hline
\end{tabular}

\subsection{Data Analysis}

Two statistical tests were carried out to analyse the sensors output during calibration. In test one, sensors from each location were individually measured once per month across seven months. A one-way repeated measures ANOVA was used (SPSS version 20: windows PC) for data from each individual location.

In test two, all the sensors regardless of location were simultaneously compared to one another for each calibration point (between months zero to seven). A one-way between-groups ANOVA test (SPSS version 20: windows PC) was used to explore the impact of location (and therefore $\mathrm{RH}$ and light levels) on the calibration drift of the sensors.

\section{Results}

All sensors performed and gave data throughout the study. The sensor output across all five locations/sensors over the seven months of the study can be found in Table 2. The data is presented as mean samples \pm 1 standard deviation. The seat sensors performed with most errors $(5.48 \pm 2.22)$ and the kitchen the least $(3.22 \pm 1.69)$. Interestingly the unpowered sensors $(3.74 \pm 1.45)$ had less errors than the drawer $(4.10 \pm 1.15)$, wall $(4.79 \pm 1.98)$ and seat sensor output.

Table 2. Errors for each sensor related to individual locations across the 7 months of the study. The output from the five sensors displayed as relative humidity (RH: each row $)$ over months $0-6(\mathrm{M}=$ month; $\mathrm{D}=$ drawer; $\mathrm{W}$ = wall; $\mathrm{S}=$ seat; $\mathrm{K}=$ Kitchen; $\mathrm{T}=$ table; $\mathrm{P}=$ powered; $\mathrm{UP}$ $=$ unpowered) of the study (columns). The data is presented as mean of 7 samples \pm 1 standard deviation.

\begin{tabular}{|c|c|c|c|c|c|}
\hline \multirow[t]{2}{*}{$M$} & \multicolumn{3}{|c|}{ Room (P) (\%RH) } & \multirow{2}{*}{$\begin{array}{l}\mathrm{K}(\mathrm{P}) \\
(\% \mathrm{RH})\end{array}$} & \multirow{2}{*}{$\begin{array}{l}\mathrm{T} \text { (UP) } \\
\text { (\%RH) }\end{array}$} \\
\hline & D & W & $S$ & & \\
\hline 0 & $\begin{array}{l}4.55 \pm \\
1.3\end{array}$ & $\begin{array}{l}4.96 \\
\pm 2.04\end{array}$ & $\begin{array}{l}4.94 \pm \\
1.77\end{array}$ & $\begin{array}{l}4.39 \pm \\
0.80\end{array}$ & $\begin{array}{l}2.49 \pm \\
1.51\end{array}$ \\
\hline 1 & $\begin{array}{l}3.05 \pm \\
0.79\end{array}$ & $\begin{array}{l}5.77 \\
\pm 5.07 \\
\end{array}$ & $\begin{array}{l}2.08 \pm \\
0.97\end{array}$ & $\begin{array}{l}4.20 \pm \\
2.26\end{array}$ & $\begin{array}{l}2.78 \pm \\
2.12\end{array}$ \\
\hline 2 & $\begin{array}{l}5.80 \pm \\
1.98 \\
\end{array}$ & $\begin{array}{l}6.14 \\
\pm 4.74 \\
\end{array}$ & $\begin{array}{l}6.25 \pm \\
6.18 \\
\end{array}$ & $\begin{array}{l}6.00 \pm \\
4.06 \\
\end{array}$ & $\begin{array}{l}6.47 \pm \\
5.86 \\
\end{array}$ \\
\hline 3 & $\begin{array}{l}3.42 \pm \\
1.51 \\
\end{array}$ & $\begin{array}{l}7.71 \\
\pm 5.41 \\
\end{array}$ & $\begin{array}{l}9.31 \pm \\
6.48 \\
\end{array}$ & $\begin{array}{l}2.31 \pm \\
1.92 \\
\end{array}$ & $\begin{array}{l}3.06 \pm \\
1.44 \\
\end{array}$ \\
\hline 4 & $\begin{array}{l}2.55 \pm \\
1.35 \\
\end{array}$ & $\begin{array}{l}1.96 \\
\pm 0.84 \\
\end{array}$ & $\begin{array}{l}6.16 \\
\pm 4.15 \\
\end{array}$ & $\begin{array}{l}1.18 \pm \\
0.91\end{array}$ & $\begin{array}{l}2.69 \pm \\
2.15 \\
\end{array}$ \\
\hline 5 & $\begin{array}{l}4.36 \pm \\
1.90 \\
\end{array}$ & $\begin{array}{l}4.05 \\
\pm 3.49 \\
\end{array}$ & $\begin{array}{l}5.55 \pm \\
2.28 \\
\end{array}$ & $\begin{array}{l}2.46 \pm \\
1.38 \\
\end{array}$ & $\begin{array}{l}4.77 \pm \\
3.26 \\
\end{array}$ \\
\hline \multirow[t]{2}{*}{6} & $\begin{array}{l}4.98 \pm \\
3.80 \\
\end{array}$ & $\begin{array}{l}2.92 \\
\pm 0.80 \\
\end{array}$ & $\begin{array}{l}4.11 \pm \\
2.02 \\
\end{array}$ & $\begin{array}{l}1.98 \pm \\
0.71 \\
\end{array}$ & $\begin{array}{l}3.94 \pm \\
2.16 \\
\end{array}$ \\
\hline & $\begin{array}{l}4.10 \pm \\
1.15 \\
\end{array}$ & $\begin{array}{l}4.79 \pm \\
1.98 \\
\end{array}$ & $\begin{array}{l}5.48 \pm \\
2.22 \\
\end{array}$ & $\begin{array}{l}3.22 \pm \\
1.69 \\
\end{array}$ & $\begin{array}{l}3.74 \pm \\
1.45 \\
\end{array}$ \\
\hline
\end{tabular}

Table 3. Each location compared across seven months.

\begin{tabular}{|l|l|}
\hline Month & $\begin{array}{l}\text { p-value(all locations } \\
\text { at each month) }\end{array}$ \\
\hline 0 & 1 \\
\hline 1 & 0.864 \\
\hline 2 & 0.989 \\
\hline 3 & 0.994 \\
\hline 4 & 0.977 \\
\hline 5 & 0.988 \\
\hline 6 & 0.783 \\
\hline
\end{tabular}

To determine the statistical changes that occurred across the seven months, a one-way repeated measures ANOVA test on SPSS (version 20) was carried out for data from each location (Table 3 ). Interestingly the kitchen $(p=0.021)$ and the seat $(p$ $=0.003$ ) sensors required the greater changes in calibration across the seven months $(p<0.05)$, the common factor possibly being exposure to higher humidity. The drawer $(\mathrm{p}=0.225)$ and wall $(\mathrm{p}=$ $0.10)$ sensors experienced negligible calibration 
drift across the measurement period $(\mathrm{p}>0.05)$ which would be consistent with low changes in ambient environments. The unpowered sensor on the table $(\mathrm{p}=0.0003)$ did however exhibit changes $(\mathrm{p}<0.05)$.

Table 4. All locations compared at each month $(\mathrm{L}=$ location; $\mathrm{D}=$ drawer; $\mathrm{W}=$ wall; $\mathrm{S}=$ seat $\mathrm{K}=$ kitchen; $\mathrm{T}=$ table $; \mathrm{NC}=$ no change $\mathrm{C}=$ change LES $=$ large effect size)

\begin{tabular}{|l|l|l|l|}
\hline L & p-value & Cohen's D test & Outcome \\
\hline $\mathrm{D}$ & 0.225 & 0.842 (LES) & $\mathrm{NC}$ \\
\hline $\mathrm{W}$ & 0.10 & $0.84($ LES) & $\mathrm{NC}$ \\
\hline $\mathrm{S}$ & 0.003 & $0.992(\mathrm{LES})$ & $\mathrm{C}$ \\
\hline $\mathrm{K}$ & 0.021 & $0.971(\mathrm{LES})$ & $\mathrm{C}$ \\
\hline $\mathrm{T}$ & 0.0003 & $0.998(\mathrm{LES})$ & $\mathrm{C}$ \\
\hline
\end{tabular}

To determine the impact of location on sensors, all sensors collectively were statistically compared at each monthly calibration using the one-way between-groups ANOVA test (SPSS, version 20 for windows PC: see Table 4). There was no apparent significant difference in sensor output in relation to location as shown on table 4.

\section{General Findings}

When individual sensors were calibrated across the seven-month period the seat and kitchen sensors experienced the largest errors. This was found in the raw data output. In the statistical analysis changes across the months were found. This may be consistent with constant exposure of some to high humidity. In the kitchen, dust and water vapour might accumulate on the sensors increasing the risk of either an electrical breakdown or simply coating the sensor and blocking it from the environment, either of which might cause a shift in offset and or sensitivity $[36,38]$. Condensation may saturate the dust coating on the sensing element and increase the conductivity between electrical circuits which could cause short circuits resulting in sensor damage, fire or electric shock [38].The sensor embedded in the seat was subjected to a high frequency of sitting (Monday to Friday, between 9 am and $6 \mathrm{pm}$ ), some of which was prolonged, which would lead to exposure to high humidity. Single day prolonged sitting measurements on humidity sensors have been performed, however none had been carried out for extended periods such as seven months [15-17]. The time line of this test was important because if sensors were used to monitor the effects of prolonged immobility in a seat, they would need to maintain calibration (or be regularly re-calibrated). This use may be important specifically for immobile people such as the spinally damaged, the extremely arthritic or the elderly who spend high levels of sitting in one place [1]. It is important to point out that humans maintain constant body temperature between $36{ }^{\circ} \mathrm{C}$ and $37.5{ }^{\circ} \mathrm{C}$; however in still, ambient temperatures of $20^{\circ} \mathrm{C}$, the skin surface temperature when clothed is between $31{ }^{\circ} \mathrm{C}$ and 36 ${ }^{\circ} \mathrm{C}[4,39]$. In a clinical study of humans on support surfaces, the RH between seat surface and buttock varied between 40 and $100 \%$ and the temperature under the ischial tuberosity's varied between 30 and $37^{\circ} \mathrm{C}[3,40]$. The humidity at the skin- support surface interface should ideally be between 40 and $65 \%$ and the interface temperature should not change by more than a few degrees [3, 40]. Taking this into consideration, and coupled with the transepidermal water loss of the subject (39.8 to 42.8 $\mathrm{gm}^{2} /$ hour) [41], the embedded sensors did experience changes over the 7 months. However it is not known what the effects of incontinence could have on this. Incontinence sensors are usually in contact with skin or embedded within a pad [42] and have an array of reported problems which include inability to discriminate between levels of moisture, high manufacturing costs, and need for additional cleaning [43]. The use of humidity sensors measuring external to the human body (as described in this article) could be an important development, however strict emphasis should be placed on correct calibration requirements. Although the unpowered sensor exhibited the least errors in calibration, placing it in an exposed environment (light and normal room environment) for seven months may have caused the changes to occur across the calibration period. This indicates that unpowered or unused sensors should ideally be stored correctly (to prevent dust build up and condensation) to avoid variations when needed for future measurement. Both the drawer and wall sensors had greater errors than the unpowered sensors, but less than the kitchen and seat sensors. However there were generally no large deviations or changes in calibration across the seven months indicating stability in all sensors. This may mean that sensors exposed to high humidity may cause their measurements to have more variation relative to the amount of humidity it is exposed to. Therefore the calibration frequency may be dependent on the environmental conditions. Sensors placed in lower humidity or normal ambient environments exhibit better stability and may be used for longer periods before calibration is 
required. When all sensors are compared with each other there were no significant differences found. The powered humidity sensor on the wall (exposed to light and ambient air), showed no difference in performance when compared to powered humidity sensor located in the drawer (darkness, lower changes in air movement) [44-45]. This means that the sensors do not appear to have been affected by dark or light environment and are able to function equally in all the environments tested in this study.

\section{Conclusions}

It is inevitable that humidity sensors may lose accuracy and require calibration at some point. The length of time could range from a few months to a year or even more depending on the usage and the environment it is in [36]. Depending on the levels of humidity exposure some sensors in this study demonstrated loss of accuracy after continuous usage (7 months). Humidity sensors appeared to show no deterioration when placed in normal room ambient environments (whether in a dark place or exposed to light). Voltage output per change in $\mathrm{RH}$ from the sensor in the kitchen did show some degree of variance, probably as a result to it having been exposed to large changes in humidity caused by usual kitchen events: i.e., steam from a frequently used kettle. Change was also seen on the sensor embedded in a seat exposed to a human subject in relatively constant daily sitting during the period of seven months. Although high exposure to humidity from the steam of the kettle may have affected the sensors, it is not known how incontinence could affect the sensors at a sitting interface. The requirement of periodic recalibration is important in addressing deviations in the sensors detection system specifically if the sensors are used for high demand applications [36] such would be the case when monitoring incontinence on a daily basis. This study would suggest that re-calibration occurs at a higher frequency when the sensor is to be used in an environment, which has higher or more varied humidity. The exact period between recalibration is dependent on many factors; this article highlights only a few of the possible elements that would affect this decision. It is suggested that all sensors should obtain regular recalibration if used continually in normal ambient environment (probably every 6 months to a year), however those used in higher humidity environments require more regular recalibration (suggested as being approximately every 3 months).

\section{Acknowledgements}

The authors would like to thank Peter Stevenson, Jonathan Williams and the team at the Faculty of Advanced Technology of the University of South Wales, for access to the climatic chamber.

\section{References}

1. Care Quality Commission 'Time to listen in care homes': Dignity and nutrition inspection programme(2012);http://www.cqc.org.uk/sites/defa ult/files/media/documents/time to listen -

are homes man report tag.pdf

2. V. Cascioli, Z. Liu, A.I. Heusch, P.W. McCarthy (2011) 'Settling down time following initial sitting and its relationship with comfort and discomfort. J. Tissue Viabil. (Nov), 20, 4 (2011) 121-29.

3. G.P Nicholson, J.T. Scales, R.P. Clark, M.L. De Calcina-Goff, A method for determining the heat transfer and water vapour permeability of patient support systems J. Med. Engin.Phys 21 (1999) 701-712.

4. M. Ferguson-Pell, H. Hirose, G. Nicholson, E. Call, Thermodynamic rigid cushion loading indenter: A buttock-shaped temperature and humidity measurement system for cushioning surfaces under anatomical compression conditions, J. Rehab. Res Dev. 46, 7 (2009) 945-56.

5. T.W. Learning, Waterproof/breathable odor-resistant seat cover Patent US 6655735, (2003); http://www.google.co.uk/patents/US6655735

6. P. Posada-Moreno, M.E. Losa Iglesias, R. Becerro de Bengoa Vallejo, I.O. Sorian, I. Zaragoza-García, C. Martínez-Rincón Influence of different bed support surface covers on skin temperature. Contemp Nurse. 39, 2 (2011) 206-20.

7. S.I. Reger, V.K. Ranganathan, V. Sahgal, Support surface interface pressure, microenvironment, and the prevalance of pressure ulcers: an analysis of the literature Ostomy. Wound. Manag. 53, 10 (2007) 50-58.

8. R.H.M. Goossens, R. H. M. Long term blood perfusion when sitting on three different cushioning materials. Delft University of Technology, Faculty of Industrial Design Engineering, Landbergstraat 15, 2628 CE, Delft, the Netherlands Blood perfusion on three cushion(2006); http://www.ergo21.com/pdf/Blood_Perfu sion_Study.pdf].

9. R.I. Barnett, J.A. Ablarde, Skin vascular reaction to short durations of normal seating. Arch. Phys. Med. Rehab. 76, 6 (1995) 533-540.

10. J.Y. Kokate, K.J. Leland, A.M. Held, G.L. Hansen, G.L. Kveen, B.A. Johnson, M.S. Wilke, E.M. Sparrow, P.A. Iaizzo Temperature-Modulated Pressure Ulcers: A porceline Model.' Arch. Phys. Med. Rehab. 76, 7 (1995) 666-673.

11. M.J. Peterson, H.V. Adkins, Measurement and Redistribution of Excessive Pressures During Wheelchair Sitting: A Clinical Report. Physical Therapy, 62 (1982) 990-994.

12. H. Freeman, B.A. Lengyel, (1938) The effects if high humidity on skin temperature at cool and warm conditions, J. Nutr., 17, 1 (1938) 43-52.

13. S.O. Brattgard, K. Severinsson, Investigations of pressure, temperature and humidity in the sitting area in $a$ wheelchair. In E. Asmussen \& K. Jorgensen (Eds.), Biomechanics VI-B (1978) 270-273. Baltimore, MD: University Park Press. 
14. G.V.B. Cochran, V. Palmieri, Development of test methods for evaluation of wheelchair cushions. Bul Pros Res. 17, 1 (1980) 9-30. 15. T.G. Cengiz, F.C. Babalik, An on-the-road experiment into the thermal comfort of car seats, App. Ergo. 38 (2007) 337-347.

16. L. Stockton, S. Rithalia. S. (2007) Pressurereducing cushions: perceptions of comfort from the wheelchair user's perspective using interface pressure, temperature and humidity measurements.

J. Tissue Viabil., 18, 2 (2007) 28-35.

17. P.W. McCarthy, Z. Liu, A.I. Heusch, V. Cascioli, Assessment of humidty and temperature sensors and their application to seating, J. Med. Engin. Tech., 33 (2009) 449-53 18. D. Bader, C. Bouten, D. Colin, C. Oomens, Pressure Ulcer Research: current and future perspectives. UK: Springer (2005). 19. National Physical Laboratory 'Good Practise Guide No. 124: The beginner's guide to humidity measurement', UK: Stephanie Bell (2012). 20. S. Solomon Sensors Handbook (2nd edn.). London: McCraw Hill (2009).

21. World Meteorological Organisation

Guide to meteorological instruments and methodsofobservation: $7^{\text {th }} \mathrm{edn}(2008)$; http://www.pme.gov.sa/en/WMO\%20References/008 MO en.pdf].

22. Y. Ding, Intelligent incontinence alarm device, WO2013185419A1.(2013);

23. J. Carney, A. Elfström and M. Bosaeus, Method and computer program for monitoring use of an absorbent product WO 2013095230 A1 (2013) 24.G. M. Ortega and M.J. Sciarra, 2012 Active onpatient sensor, method and system US20120119912A1,(2012)

25. R. Yonezawa, H. Ogawa, K. Mukai, K. Bioinformation detecting device of bed mattress (2009); Patent 2009-072396

26. T.M. Ales, A.M. Long, C.R. Tomsovic, D.H. Nhan, S.A. Weber, and J.C. Cohen. (2010) Remote detection systems for absorbent articles. WO 2010076679A3(2010)

27. Z. Chen, C. Lu,Humidity Sensors: a review of materials and mechanisms Sensor Letters 3(2005) 274-295.

28. Y.F. Lin, T.I. Yeh, K.H. Chan, T.S. Chen, The automatic calibration system of humidity fixed points at CMS. Measurement, 19, 2(1996)65-71. 29. D. K. Roveti, Choosing a humidity sensor:a review of 3 technologies Sensors, 18(2001)54-58. 30. P. Su, R. Wu, (2004) Uncertainty of humidity sensors testing by means of divided-flow generator. Measurement, 36 (2004) 21-27.

31. G. M. S. De Silva, Basic Metrology for ISO 9000 Certification, Butterworth-Heinmann. (2002).
32. United Kingdom Accreditation Service: ISO 17025(UKAS)(2013); http://www.ukas.org/calibrati on/aboutus.asp.

33 ISO 10012-1:1992 Quality assurance requirements for measuring equipment - Part 1: Metrological confirmation system for measuring equipment

34 T. Lu, C. Chen. Uncertainty evaluation of humidity sensors calibrated by saturated salt solutions. Measurement, 40 (2007) 591-599.

35. R. Schellenberg, (2002), The Trouble with humidity: the hidden challenges of RH calibration, Veriteq instruments;

http://www.vaisala.com/Vaisala\%20Documents/Wh ite\%20Papers/lsh-Trouble-with-Humidity.pdf 36. S. Cavlier, S. (2012) 'White Paper: Relative humidity sensor behaviour and care' (2012). Colarado: Delmhorst Instrument Co.; http://www.delmhorst.com/Documents/PDFs/Produ ct-Support/White-Paper-Relative-Humidity-Sensor Behavior-an.pdf.

37. Honeywell Internation Inc. Data sheet: HIH4000 Series Humidity Sensors (2014);

http://www.honeywell.com/sensing].

38. D. Lohbeck, Design for dust: Product safety'. National Instruments, Test and Measurement World Cl2008); http://www.tmworld.com.

39. S. Cheung, Advanced Environmental Exercise Physiology: Advanced Exercise Physiologies Series, USA: Library of Congress Cataloging-inpublication (2010).

40. G. V. B. Cochran,. and V. Palmieri, Development of test methods for evaluation of wheelchair cushions. Bul Pros Res. (spring), 17, 1 (1980) 9-30.

41. M. Gray, Incontinence associated dermatitis in the elderly patient: assessment, prevention and

Management. New journal of geriatric care management(2014).

http://www.gcmjournal.org/2014/05/14/incontinenc e-associated-dermatitis-in-the-elderly-patient assessment-prevention-and-management/

42. K. Getliffe, M. Dolman, Promoting Continence: $A$ clinical and research resource. 3rd edition (2007) USA: Churchill Livingstone

43. P.M. Lewis, K.M .Carey, A.M. Cottenden, D.A. Barda, P.Curran,D. Black, Incontinence monitoring and assessment US20120268278A1 (2012)

44. M. Matsuguchi, E. Hirota, T. Kuroiwa, S. Obara, T. Ogura, Y. Sakai. Drift phenomenon of capacitive-type relative humidity sensors in a hot and humid atmosphere. Journal of the ElectrochemicalSociety, 147, 7 (2000) 2796-2799. 45. Vaisala Humidity measurement in test chambers and incubators-questions and answers (2010). http:/www.vaisala.com/VaisalaDocuments/Applica tionnotes/HumidityMeasurementinTestChambers FAQs-application-note-B210927EN-A.pdf. 